\title{
EXTRAGINGIVAL PYOGENIC GRANULOMA IN AN ELDERLY FEMALE: A CASE REPORT
}

Maina Bekal' ${ }^{1}$ Usha $\mathrm{H}^{2}$

\section{HOW TO CITE THIS ARTICLE:}

Maina Bekal, Usha H. "Extragingival Pyogenic Granuloma in an Elderly Female: A Case Report". Journal of Evolution of Medical and Dental Sciences 2015; Vol. 4, Issue 68, August 24; Page: 11906-11908,

DOI: $10.14260 /$ jemds/2015/1716

ABSTRACT: Pyogenic granuloma is a relatively common benign mucocutaneous lesion occurring intra orally or extra orally. Oral pyogenic granuloma is a kind of inflammatory hyperpalsia resulting from different stimuli such as chronic local denture irritation, drug reaction, hormonal variations and responses to grafts. The exact etiopathogenesis remains unknown. It predominantly occurs in young females in second decade of life. Extragingival occurrence is usually rare. Although excisional surgery is the treatment of choice, other treatments such as the use of $\mathrm{Nd}$ : Yag laser, flash lamp pulsed dye laser, cryosurgery, intralesional injection of ethanol or corticosteroid and sodium tetradecyl sulfate sclerotherapy have also been proposed. Since this lesion is of high frequency in the oral cavity, especially during pregnancy, we present a case with pyogenic granuloma in an elderly female patient which is seen rarely in this age group and unrelated to pregnancy as the literature presents.

KEYWORDS: Pyogenic Granuloma, Oral Cavity, Elderly Patient, Buccal Mucosa.

INTRODUCTION: Hullihen described the first case of pyogenic granuloma in English literature in 1844. ${ }^{1}$ Hartzell in 1904 gave the current term of "pyogenic granuloma" or "granuloma pyogenicum". ${ }^{2}$ Pyogenic granuloma (Also known as "Granuloma gravidarum" and "Pregnancy tumor") is a type of inflammatory hyperplasia. The name pyogenic granuloma is a misnomer since the condition is not associated with pus and does not represent a granuloma histologically. ${ }^{3}$ Some authors use the term lobular capillary hemangioma for this lesion. ${ }^{4}$

Although it may occur in all ages, it is predominant in $2^{\text {nd }}$ decade of life with female predilection. Recent study shows occurrence in $6^{\text {th }}$ decade of life. ${ }^{5}$

Approximately one third of the lesion occurs after trauma, so for extragingival lesion history of trauma is not unusual. Poor oral hygiene may be precipitating factor. In pregnancy hormonal imbalance increases organisms response to irritation the chances of development of pyogenic granuloma. However the lesion is rarely seen in woman with good oral hygiene in pregnancy. Factors such as nitric oxide synthase, vascular endothelial growth factor, connective tissue growth factor are known to be involved in angiogenesis and rapid growth of pyogenic granuloma. ${ }^{5}$

CASE REPORT: A 70 years old female reported to the department of dentistry with a chief complaint of growth in the left buccal mucosa since 3-4 years. The patient gave a history of cheek bite following which she developed the lesion. The lesion was initially small in size and had gradually increased to the present size which was causing problem while mastication as the lesion was coming between both the jaws while chewing.

On examination a well-defined growth was seen on the left buccal mucosa of about $2 \times 2 \mathrm{cms}$ in dimension. The mucosa overlying the growth was smooth, pale pink with areas of erythema with no pus discharge or bleeding. The tooth adjacent to the lesion was sharp. 


\section{CASE REPORT}

On palpation, the growth was pedunculated, firm in consistency, non-tender. There was no bleeding on provocation. Irritational fibroma was given as the differential diagnosis and excisional biopsy under local anaesthesia followed by histopathological evaluation was planned.

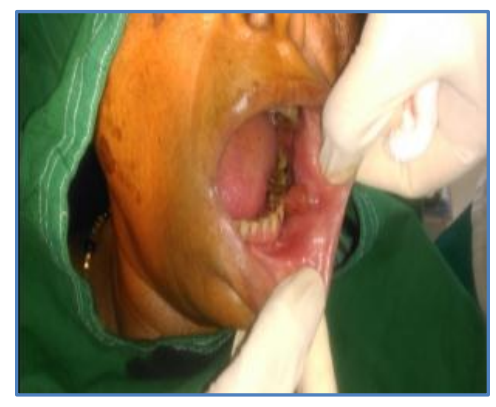

Fig. 1

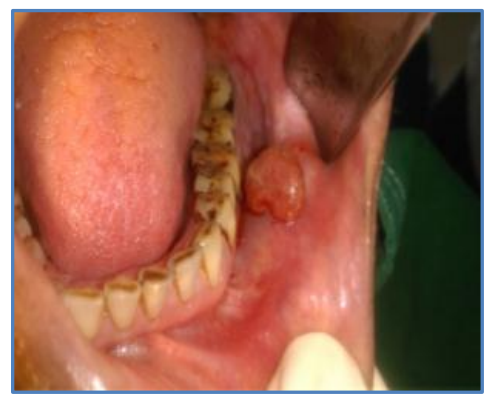

Fig. 2

Histopathological Report: Lesional tissue comprising of proliferating blood vessels separated by fibrotic tissue, extensive surface ulceration with neutrophilic inflammatory cell infiltrate, focally keratinized squamous epithelium.

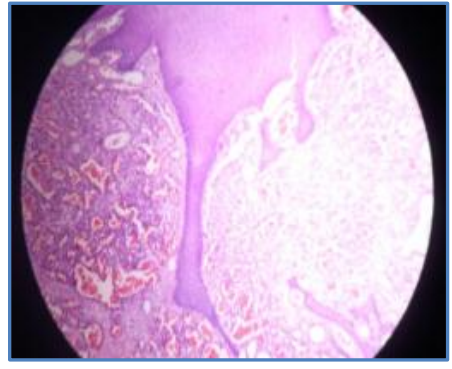

Fig. 3

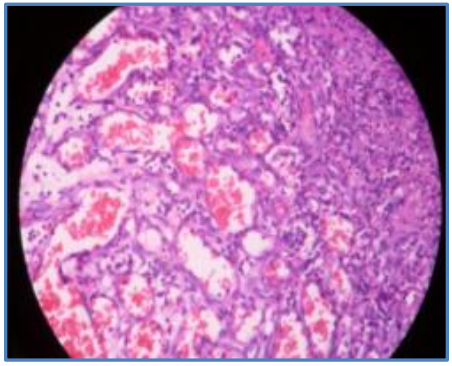

Fig. 4

Following excision the biopsied site healing was satisfactory. There was no recurrence 6 months after the excision.

DISCUSSION: The pyogenic granuloma is a relatively common tumor like exuberant tissue response to localized irritation or trauma. The name pyogenic granuloma is a misnomer since the condition is not associated with pus. ${ }^{3,6,7}$ The incidence of pyogenic granuloma has been described as between 26.8 and $32 \%$ of all reactive lesions. In the oral cavity pyogenic granulomas show a striking predilection for the gingiva, with interdental papillae being the most common site in $70 \%$ of the cases. In the present case, it is arising from the buccal mucosa. Gingival irritation and inflammation that result from poor oral hygiene, dental plaque and calculus or overhanging restorations may be precipitating factors in many cases. Pyogenic granulomas of head and neck are uncommonly seen. Extragingivally, the pyogenic granuloma occurs in the area of frequent trauma sites, such as lower lip, tongue, palate and buccal mucosa. In the present case, the constant trauma inflicted by adjacent sharp cusp tip could have been the etiology behind the growth on the buccal mucosa. 
Although pyogenic granuloma can be diagnosed clinically with considerable accuracy, histopathological investigation aid in confirming the diagnosis and treatment. All clinically suspected pyogenic granulomas must be biopsied to rule out other conditions, such as irritational fibroma, hemangioma, Kaposi's sarcoma, leiomyoma, amelanotic melanoma, basal metastatic carcinoma, and squamous cell carcinoma.

Treatment of pyogenic granuloma consists of conservative surgical excision, which is usually curative. There is a relatively high rate of recurrence (about 15\%) after simple excision. Although, these are reactive hyperplasias, they have a relatively high rate of recurrence after simple excision, especially in pregnant patients. Recurrences after the surgery of extragingival pyogenic granuloma is however uncommon.

\section{REFERENCES:}

1. Hullihen SP. Case of aneurism by anastomosis of the superior maxillae. Am J Dent Sci 1844; 4: 160 - 2. Journal of Indian Society of Periodontology-Vol. 17, Issue 4, Jul-Aug 2013.

2. Hartzell MB. Granuloma pyogenicum. J Cutan Dis Syph, 1904; 22: 520-5.

3. Karthikeya Patil, Mahima VG, Lahari K: Exragingival pyogenic granuloma. Indian Journal of Dental Research, 2006, 17(4):199-202.

4. Akyol MU, Yalciner EG, Dolan AI: Pyogenic granuloma (lobular capillary hemangioma) of the tongue. Int J Pediatr Otorhinolaryngol 2001, 58(3): 239-241.

5. Hamid jafarzadeh et al Oral pyogenic granuloma - A review, Journal of Oral Science, vol 48, no.4, 167-175,2006.

6. Nevile BW, Damm DD, Allen CM, Bouquot JE: Oral and Maxillofacial Pathology Second edition. W.B. Saunders co; 2004: 444-449.

7. Maryam Amirchaghmaghi Extragingival pyogenic granuloma: A case report Cases Journal 2008, 1: 371.

\section{AUTHORS: \\ 1. Maina Bekal \\ 2. Usha $\mathrm{H}$.}

\section{PARTICULARS OF CONTRIBUTORS:}

1. Assistant Professor, Department of Dentistry, Akash Hospital.

2. Assistant Professor, Department of Dentistry, Akash Hospital.

FINANCIAL OR OTHER COMPETING INTERESTS: None
NAME ADDRESS EMAIL ID OF THE CORRESPONDING AUTHOR:

Dr. Maina Bekal, Akash Hospital Staff Quarters, Prasannahalli, Near International Airport, Devanahalli, Bengaluru Rural-562110. E-mail: drmainabekal@yahoo.com

Date of Submission: 06/08/2015. Date of Peer Review: 07/08/2015. Date of Acceptance: 20/08/2015. Date of Publishing: 24/08/2015. 